\title{
Dirichlet process model for joint haplotype inference and GWAS
}

\author{
Avinash Das Sahu ${ }^{1,2^{*}}$, Sridhar Hannenhalli, ${ }^{1,2}$ \\ From Beyond the Genome 2012 \\ Boston, MA, USA. 27-29 September 2012
}

Identification of causal genomic mutations that underlie disease phenotypes remains a key problem in the field of medical informatics. With the advent of new sequencing technologies and decreasing cost of human genotyping, it is now possible to study genotype-phenotype interactions, such as genome-wide association studies (GWAS), at the population level. However, due to large genomic variance and linkage disequilibrium, genetic diversity of a complete human population cannot be captured by a limited number of clusters. Furthermore, application of current haplotype inferencing (phasing) methods to rare genomic variance, such as disease-related alleles, is not reliable. Hence, a satisfactory method for deleterious mutation identification remains largely elusive. Here we present a non-parametric Bayesian model that jointly infers haplotypes and identifies deleterious mutations, taking into consideration genomic variance in the human population. The model is based on the Dirichlet process, which can capture genomic variance by modeling it with nonbounded numbers of clusters.

\footnotetext{
Author details

${ }^{1}$ University of Maryland, College Park, MD 20740, USA. ${ }^{2}$ University of

Maryland Institute for Advanced Computer Studies, MD, USA.
}

Published: 1 October 2012

doi:10.1186/1753-6561-6-S6-P49

Cite this article as: Sahu and Hannenhalli: Dirichlet process model for

joint haplotype inference and GWAS. BMC Proceedings 2012 6(Suppl 6): P49.

Submit your next manuscript to BioMed Central and take full advantage of:

- Convenient online submission

- Thorough peer review

- No space constraints or color figure charges

- Immediate publication on acceptance

- Inclusion in PubMed, CAS, Scopus and Google Scholar

- Research which is freely available for redistribution
() Biomed Central

'University of Maryland, College Park, MD 20740, USA

Full list of author information is available at the end of the article 